\title{
El derecho a la vida y a la protección de la salud en las medidas adoptadas en España como consecuencia de la covid-19: Una reflexión sobre su oportunidad
}

The right to life and health protection in the measures adopted in spain as a consequence of covi-19: a reflection on its opportunity

Francisca Ramón FernándeZ

Universitat Politècnica de València frarafer@urb.upv.es ${ }^{1}$

\begin{abstract}
Resumen: En el presente trabajo se analiza las medidas adoptadas en España a raíz del estado de alarma por la COVID-19 y el derecho a la vida y la protección de la salud con una reflexión sobre la oportunidad de las mismas. Se parte de la regulación establecida en el cuerpo normativo, así como la postura de la doctrina más reciente para analizar las restricciones que se han establecido a determina-
\end{abstract}

1 Profesora titular de Derecho civil en la Universitat Politècnica de València. Licenciada y Doctora en Derecho por la Universitat de València. Correo electrónico: frarafer@urb.upv.es

Trabajo realizado en el marco del Proyecto $\mathrm{I}+\mathrm{D}+\mathrm{i}$ «Retos investigación» del Programa estatal de I+D+i orientado a los Retos de la Sociedad del Ministerio de Ciencia, Innovación y Universidades: RTI2018097354-B-10o (2019-2022). Investigadores principales: Dra. Da. Luz M. Martínez Velencoso. Catedrática de Derecho Civil. Universitat de València y Dr. D. Javier Plaza Penadés. Catedrático de Derecho Civil. Universitat de València, $\mathrm{y}$ del Proyecto de I+D+i Retos MICINN "Derechos y garantías frente a las decisiones automatizadas en entornos de inteligencia artificial, IoT, big data y robótica" (PID2019-108710RB-Ioo, 2020-2022). Investigador principal: Dr. D. Lorenzo Cotino Hueso. Catedrático de Derecho Constitucional. Universitat de València.

Artículo recibido el 05.04.2020 y aceptado para publicación el 05.08.2020. 
dos derechos y las medidas que se han adoptado para limitar las actividades de la vida habitual, con la finalidad de proteger la salud de las personas en la situación de crisis sanitaria. Se atenderá en el estudio, especialmente, a diversas situaciones como es el caso de los colectivos vulnerables, y los ciudadanos, con la finalidad de determinar la relación entre la protección de la salud y el derecho a la vida, así como si ello ha constituido o no una suspensión de sus derechos constitucionales.

Palabras clave: Constitución española; protección; salud; estado de alarma; coronavirus

Abstract: This paper analyzes the measures adopted in Spain as a result of the state of alarm by COVID-19 and the right to life and health protection with a reflection on their timeliness. It starts from the regulation established in the regulatory body, as well as the most recent doctrine position to analyze the restrictions that have been established to certain rights and the measures that have been adopted to limit the activities of normal life, in order to protect the health of people in the situation of health crisis. The study will attend, especially, to various situations such as the case of vulnerable groups, and citizens, in order to determine the relationship between health protection and the right to life, as well as whether this has constituted or not a suspension of your constitutional rights.

Keywords: Spanish constitution; protection; Health; alarm status; coronavirus

\section{Introducción}

En el momento de la redacción del presente trabajo, en España, estamos en un estado de alarma que fue declarado por Real Decreto 463/2020, y que ha sido prorrogado por los Reales Decretos 476/202O; 487/2020; 492/2020; 514/2020; 537/2020 y 555/2020. Esta situación se ha producido a causa de la situación de la pandemia del coronavirus, después de que la Organización Mundial de la Salud estableció la situación de emergencia de salud pública ocasionada por el COVID-19 a pandemia internacional, el 11 de marzo de $2020 .{ }^{2}$ Se trata, pues, de una situación global ${ }^{3}$, ya que no se ha limitado a nuestro país, sino que en estos momentos muchos

2 Organización Mundial de la Salud (2020). Véase también: López (2020), p. 7; Trilla (2020), p. 176; Marazuela (2020), p. 56; Ramos (2020), p. 225; Lizaraso y Del Carmen (2020), p. 4-5.

3 Alpuche (2020), p. 123. 
países del mundo occidental se encuentran en la misma situación, tras el primer caso detectado en Wuhan.

Nos encontramos, pues, en una situación de emergencia, teniendo en cuenta que este término se ha ampliado en los últimos años abarcando situaciones ambientales, hídricas, crisis económicas-financieras. ${ }^{4}$ Estamos ante un escenario imprevisible que afecta a todos los sectores de la sociedad, tanto económico como social. ${ }^{5}$ La situación de la ciudadanía ha cambiado radicalmente y para la mayoría de nosotros, del sur de Europa, nunca hemos sufrido un tiempo de pandemia. Ello nos hace reflexionar sobre los derechos constitucionales, en concreto sobre uno de los principios rectores de la política social y económica del artículo 43 de la Constitución Española de 1978, que reconoce el derecho a la protección de la salud.

En el presente trabajo nos proponemos realizar un análisis de la legitimación y proporcionalidad de las medidas que se han adoptado con el fin de proteger el derecho a la protección de la salud en relación al derecho a la vida, teniendo en cuenta la declaración del estado de alarma regulado en el artículo 116 de la Constitución Española.

Los objetivos que vamos a desarrollar van a ser los siguientes:

a) Determinar el contenido del derecho a la protección de la salud en la Constitución española;

b) Establecer la relación entre el derecho a la vida y el derecho a la protección de la salud;

c) Análisis de las medidas adoptadas para la protección de la salud en la declaración del estado de alarma por la crisis sanitaria por la COVID-19;

d)Determinar si las restricciones que se han establecido en relación a los derechos han supuesto una suspensión de los mismos teniendo en cuenta lo dispuesto en el texto constitucional español y si el estado de alarma decretado es tal o un estado de excepción encubierto;

e) Estudiar la situación en determinados colectivos vulnerables con la finalidad de determinar la relación entre la protección de la salud y el derecho a la vida y el alcance del mismo;

4 Carbonell (2008), p. 44; Ríos (2009), p. 6 y Robledo (2010), p. 250;

5 Serrano (2020), p. 111. 
f) Reflexionar sobre las medidas adoptadas para la protección de la salud y el derecho a la vida con motivo de la crisis sanitaria por la COVID-19 y su oportunidad.

Para ello vamos a utilizar la metodología de analizar la legislación aplicable, en concreto las normas que se han promulgado más recientemente, junto con la postura de la doctrina que ha abordado los principales aspectos que vamos a tratar en el presente estudio, con la finalidad de obtener unas conclusiones pertinentes referentes a la configuración del derecho a la vida y el derecho a la protección de la salud en una situación excepcional como es la que nos encontramos.

\section{El Derecho a la protección de la salud y su regulación en la Constitución española}

El Derecho a la protección de la salud se encuentra regulado en el Título I, "De los derechos y deberes fundamentales", en el Capítulo Segundo, que se refieren a "Derechos y libertades", en la Sección $2^{\text {a }}$. relativa a "De los Derechos y deberes de los ciudadanos", y en concreto en el artículo 43 del texto Constitucional español.

Su ubicación dentro de la Constitución Española ha sido objeto de debate en relación con la consideración de derecho fundamental. Así, la doctrina ${ }^{6}$ indicó que hay que tener en cuenta que hay intuiciones acerca de su consideración o no como tal derecho: la jerarquía jurídica, y su consignación en tratados internacionales de Derechos Humanos, como la Declaración Universal de Derechos Humanos, el Pacto Internacional de Derechos Civiles y Políticos, el Pacto Internacional de Derechos Económicos, Sociales y Culturales, la Convención Europea de Derechos Humanos, la Convención Americana de Derechos Humanos y la Carta Africana de Derechos Humanos y Derechos de los Pueblos. Teniendo en cuenta la Déclaration des droits de l'homme et du citoyen (1789), y el Bill of Rights (1791).

Este precepto indica que se reconoce el derecho a la protección de la salud. Junto con ese reconocimiento se establece una competencia de los poderes públicos para organizar y tutelar la salud pública a través de medidas preventivas y de las prestaciones y servicios necesarios. Y se indica que será una ley la que establecerá los derechos y deberes de todos al respecto.

Sin embargo, este precepto, no se detiene en los colectivos altamente vulnerables y que son los que están especialmente afectados por la situación en la que

6 Alvarado (2015), p. 392 y 393. 
nos encontramos en el tiempo de pandemia. Entiéndase, las personas de la tercera edad, menores, inmigrantes, personas que sufren violencia de género. ${ }^{7}$

Debe ser protegido este derecho en el ámbito estatal, y ser considerado como un derecho de carácter inclusivo, ya que todas las personas tiene el derecho al mismo, sin ningún tipo de excepción. ${ }^{8}$

Este derecho a la protección de la salud se contempla, en el ámbito comunitario, en la Carta de los Derechos Fundamentales de la Unión Europea ${ }^{9}$ dentro de lo que se consideran como derechos relacionados con la responsabilidad social ${ }^{10}$, en su artículo 35, que precisa: “Toda persona tiene derecho a la prevención sanitaria y a beneficiarse de la atención sanitaria en las condiciones establecidas por las legislaciones y prácticas nacionales. Al definirse y ejecutarse todas las políticas y acciones de la Unión se garantizará un alto nivel de protección de la salud humana”.

Debe ponerse en relación con los deberes subjetivos, ya que precisamente va a depender del cumplimiento de estos el mantenimiento del derecho. ${ }^{11}$ La acción estatal no va a ser suficiente para ello, y es necesario la implicación de los sujetos, que son a su vez, acreedores de ese mismo derecho.

El derecho a la protección de la salud dispone de un contenido específico y mínimo, estableciendo unas garantías para las prestaciones de salud que se traducen en el acceso, calidad, oportunidad y costo. ${ }^{12}$ La necesaria diferenciación entre el derecho a la salud y el derecho a la protección de la salud, éste último, contemplado en la Constitución española, tiene consecuencias notables como ha puesto de manifiesto la doctrina. ${ }^{13}$ Por un lado, el derecho a la salud como derecho constitucional con un contenido o significado, con la limitación al legislador de adoptar determinadas normas y la obligación de instituir ciertas normas, con lo que se establece la discrecionalidad para la política sanitaria; y, por otro lado, si no se reconoce el derecho a la salud en la Carta Magna y solo posee rango legal,

7 A diferencia de otros textos constitucionales, por ejemplo, podemos citar el caso de Uruguay, que menciona de forma expresa a los indigentes o carentes de recursos suficientes (artículo 44), como indica GaraT (2018), p. 321.

8 Así lo indica Pérez (2020), p. 128.

9 Véase: Alegre (2004), p. 63.

10 НAMULÁK et al. (2018), p. 168.

11 SANT'Ana (2014), p. 16.

12 ZÚÑIGA (2011), p. 54; Ferrer et al. (2012), p. 180. Se muestra de forma clara en el caso de la población más vulnerable como señalan ALLARD et al. (2016), p. 120, y la protección adecuada de los derechos fundamentales no es una facultad atribuida a los poderes públicos, debiendo actuar bajo el principio de proporcionalidad (p. 124).

13 Figueroa (2013), p. 2. 
la discrecionalidad abarcará los contenidos y límites del mismo. ${ }^{14}$ Como señala Figueroa, la recuperación de la salud es parte del derecho a la salud. ${ }^{15}$

Por su parte, Alventosa siguiendo a Talavera y a Vidal, considera que la protección de la salud desde el prisma constitucional se entiende desde una doble óptica: como un bien común o social y como un bien individual de especial relevancia. ${ }^{16}$

Su contenido se entiende como el derecho de toda persona para disfrutar del bienestar tanto físico, mental como social, y ello conlleva una disponibilidad, accesibilidad y calidad de los bienes y servicios relacionados con la salud de una forma igualitaria y sin discriminación. ${ }^{17}$

\section{El Derecho a la vida y su relación con el Derecho a la protección de la salud}

El derecho a la protección de la salud también se pone en relación con el derecho a la vida. Es decir, si esa protección que se contempla en el texto constitucional español significa que el Estado tiene la obligación de conceder lo esencial para mantener la vida de sus ciudadanos. ${ }^{18} \mathrm{Si}$ acudimos al artículo 15 de la Constitución Española, que se encuentra dentro del Título I, "De los derechos y deberes constitucionales", en el Capítulo Segundo, "Derechos y libertades", dentro de la sección $1^{\text {a }}$, referente a "De los derechos fundamentales y de las libertades públicas", se recoge el derecho fundamental a la vida y a la integridad física y moral. Nos encontramos ante un derecho de la personalidad o fundamental, con una protección especial como tales derechos que son. ${ }^{19}$

La doctrina interpreta el precepto entendiendo que el derecho a la vida se debe interpretar como que nadie nos puede privar de forma arbitraría de la misma. Sin embargo, no se admite la consideración de que ese derecho a la vida se trate de un derecho absoluto con una obligación positiva estatal de garantizar el mantenimiento de la misma. ${ }^{20}$ Esta interpretación que se rechaza sería interesante en el caso de la pandemia que estamos padeciendo, ya que, precisamente la protección del derecho a la salud, se interpretaría como el derecho a mantener con vida a las

\footnotetext{
14 Figueroa (2013), p. 2. 15 Figueroa (2013), p. 287. 16 Alventosa (2020), p. 111; Talavera (2008), p. 125 y sigs.; Vidal (2015), p. 5 y sigs.

17 PÉrez (2020), p. 128.

18 ZÚÑiga (2011), p. 39.

19 Alventosa (2020), p. 111.

20 ZÚÑIGA (2011), p. 39. Véase también: KNIGHT (2015), p. 95.
} 
personas, como derecho fundamental, y la obligación del Estado de garantizar que se va a mantener a los sujetos con el signo vital derivado de su derecho a la protección de la salud y el derecho a la vida, pudiendo exigir responsabilidad en el caso de no cumplimiento.

Desde luego la equiparación entre derecho a la salud y el derecho a la vida no se contempla en el texto constitucional, ya que lo que indica el artículo 43 de la Constitución española es el derecho a la protección de la salud, pero no un derecho absoluto a la salud de los ciudadanos, ya que supondría una garantía absoluta de evitar enfermedades y otros padecimientos.

En el caso de la pandemia sí que se ha producido un conflicto respecto al derecho a la protección de la salud y el derecho a la vida, con unas consecuencias sociales importantes, dado que se ha priorizado la atención sanitaria en determinados casos en detrimento de otros.

Como indica Pérez, ${ }^{21}$ se plantea un dilema bioético en el derecho a la vida en los casos de una pandemia, como ha sucedido en esta ocasión. Esta autora muestra su experiencia en México, pero que puede ser extrapolable a España. Vamos a verlo con más detalle. La situación de pandemia ha provocado una saturación en los hospitales, y se ha aplicado un protocolo de atención que ha determinado la selección de pacientes. En este caso el principio de justicia social no se ha aplicado, ya que en la decisión de a quién salvar, y a quién facilitar los recursos no ha sido por igual. Este principio de justicia social se refiere a la igualdad del valor de la vida de las personas y la distribución de recursos escasos en el supuesto de una pandemia se orientará a salvar el mayor número posible de vidas.

Esta situación de escasez de recursos genera problemas de distribución y de disfrute de oportunidades, que en el caso de la crisis sanitaria se ha traducido en la posibilidad de utilizar un respirador o el acceso a la unidad de cuidados intensivos. Se plantea si el derecho a la vida lo tienen unas personas más que otras en función de su edad, condición social, o comorbilidad. Si bien es cierto que el derecho a la vida no puede ser limitado ni restringido, ni aplicarse ningún tipo de discriminación. En los casos de emergencias por una crisis en las que los recursos han escaseado, sí que se ha limitado. Se ha aplicado el principio de salvar al mayor número de personas que tuvieran mayor esperanza de vida. Ello ha supuesto un conflicto social muy importante, que ha derivado en procedimientos judiciales.

21 Sigo el argumento de Pérez (2020), p. 133. 


\section{La declaración del estado de alarma por la crisis sanitaria del COVID-19 y sus consecuencias respecto de los derechos fundamentales}

La regulación del estado de alarma se establece en la Ley Orgánica 4/1981, junto con los estados de excepción y sitio. Esta declaración excepcional de estado de alarma se produce cuando circunstancias extraordinarias no permiten el mantenimiento de la normalidad en el país.

En dicha situación, se adoptan una serie de medidas, limitadas temporalmente, que se consideren como indispensables para asegurar el restablecimiento de la normalidad, y deben aplicarse proporcionalmente a las circunstancias. Y las medidas que se han adoptado han afectado al derecho a la protección de la salud. ${ }^{22}$

Hay que tener en cuenta que la proporcionalidad de las medidas que se adopten debe ir en consonancia con el sacrificio que supone su adopción ${ }^{23}$ y no sólo en el ámbito de los derechos de los ciudadanos, aunque el origen del principio es la protección de los derechos de los particulares, sino también en el ámbito de las competencias, por lo que pueden adoptarse por el ejecutivo medidas en estado de alarma sobre cualquier materia (sanitaria, servicios sociales, transporte...), pero ello es lícito en tanto en cuanto el sacrificio de competencias de ámbito autonómico o local sea proporcional, es decir, cuando se sacrifica en la menor medida el reparto competencial establecido constitucionalmente.

En el caso de la crisis sanitaria por la pandemia, se ha decretado el estado de alarma de forma total en todo el territorio español, por la razón de alteración grave de la normalidad.

Esta situación de estado de alarma es diferente a lo que se considera como "extraordinaria y urgente necesidad" ${ }^{24}$ que justifica el "papel legislador" del Gobierno a través del artículo 86 de la Constitución española, que preceptúa que en dichos supuesto, "el Gobierno podrá dictar disposiciones legislativas provisionales que tomarán la forma de Decretos-leyes y que no podrán afectar al ordenamiento de las instituciones básicas del Estado, a los derechos, deberes y libertades de los ciudadanos regulados en el Título I, al régimen de las Comunidades Autónomas ni al Derecho electoral general".

22 Pigo (2020).

23 Velasco (2020), p. 84.

24 Velasco (2020), p. 78. 
Siguiendo a Cotino ${ }^{25}$, en relación a los derechos fundamentales, las garantías dogmáticas de los derechos son diferentes en distintas situaciones que se pueden contemplar: a) Suspensión del derecho fundamental; b) No suspensión del derecho fundamental; c) Derecho fundamental bajo régimen de excepción; d) Derecho fundamental bajo régimen ordinario. En definitiva, se produce una limitación en los derechos fundamentales. ${ }^{26}$

\section{Análisis de las medidas para la protección de la salud adoptadas durante el estado de alarma por la crisis sanitaria del COVID-19}

Con la finalidad de proteger la salud y seguridad, el Gobierno aprobó una serie de medidas a través de distintos Reales Decretos, que no han supuesto una suspensión de los derechos y libertades tal y como indica el artículo 55 de la Constitución Española, ya que esta situación sólo se contempla en los casos de estado de excepción o de sitio, y no de alarma.

Como indica la doctrina, durante el estado de alarma se pueden producir graves restricciones de los derechos por el régimen excepcional que se ha adoptado, sin necesidad de producirse una suspensión de los derechos. ${ }^{27}$

En este sentido, los derechos que se reconocen en los siguientes preceptos se mantienen: a) Artículo 17 de la Constitución Española respecto al derecho a la libertad y seguridad; b) Artículo 18, apartado 2 y 3, referente a la inviolabilidad del domicilio, y el secreto de las telecomunicaciones; c) Artículo 19, sobre el derecho de elección de residencia y circulación; d) Artículo 20, apartados 1, a) y d), en cuanto al derecho a expresar y difundir libremente los pensamientos, ideas y opiniones de forma oral, escrita o por cualquier otro medio de reproducción, y a comunicar o recibir libremente información veraz por cualquier medio de difusión, y apartado 5, respecto al secuestro de publicaciones, grabaciones y otros medios solamente en virtud de resolución judicial; e) Artículo 21, respecto al derecho de reunión pacífica y sin armas; f) Artículo 28, apartado 2, en cuanto al derecho a la huelga de los trabajadores; y g) Artículo 37, apartado 2, referente al derecho de los trabajadores y empresarios a la adopción de medidas de conflicto colectivo.

25 Cotino (2020b), p. 91.

26 Tórtora (2010), p. 169. Cfr.Poli (2012), p. 320; Nogueira (2005), p. 15.

27 Cotino (2020a), p. 2. Véase también Requejo (2001), p. 105. 
El Real Decreto 463/2020, modificado posteriormente por el Real Decreto 465/2020, contempla una serie de pautas para la protección de la salud, en relación con lo preceptuado en los artículos 30 y 43.2 de la Constitución Española. Ello se incardina en la situación de grave riesgo y la necesidad de adoptar medidas preventivas estableciéndose un deber de cumplimiento por parte de los ciudadanos.

Estas medidas preventivas que se han adoptado han sido el aislamiento (separando a las personas infectadas por el virus, para evitar el contagio del resto, teniendo en cuenta las circunstancias, sintomatología y estado de salud, pueden ser aisladas en centros médicos o bien en el domicilio); la cuarentena (limitando la libertad de movimientos de la población tanto asintomática como de la que ha estado expuesta a un portador del virus, para evitar el riesgo de contagio y controlar los focos); el rastreo de portadores (para seguir la trazabilidad del virus y evitar el contagio); la restricción laboral (en los casos de actividad no esencial, con la misma finalidad).

Vemos que las medidas adoptadas eran restrictivas de la libre circulación de personas, y se justificaban en la necesidad de evitar una propagación de la enfermedad que conllevara también el colapso del sistema público de salud.

Llama la atención y también lo ha notado la doctrina ${ }^{28}$ que el Real Decreto 463/2020 modifica un precepto de una Ley Orgánica, en concreto la Ley Orgánica 3/1986, parece posible en el ámbito jurídico hacerlo por "una afectación menor al derecho de propiedad de un número limitado de productos, que son indispensables para una mejor lucha para la crisis sanitaria”.

Vamos a ver con detalle algunos aspectos en relación con el derecho a la protección de la salud.

a) Medidas adoptadas en el ámbito personal de los sujetos en relación con la movilidad y la libertad de circulación. El ciudadano ve limitada, que no suspendida, la libertad de circulación, ya que se contemplan los supuestos en los que puede acceder a la vía pública, y también en amparo de la salud pública se prevé que se pueda acordar el cierre a la circulación de carreteras o tramos de las mismas. Plantea la cuestión de si esa limitación, es decir, el confinamiento como restricción a la libertad de la persona ${ }^{29}$, va en contra de derecho fundamental a la libertad y seguridad que se contempla en el artículo 17 de la Constitución española, que se encuentra en el Título I "De los derechos y deberes fundamentales",

28 Álvarez (2020), p. 14; Nogueira (2020), p.25.

29 Cotino (2020a), p. 7. 
dentro del Capítulo Segundo, en la sede de la Sección $1^{\text {a }}$, relativa a "De los derechos fundamentales y las libertades públicas", y que indica que toda persona tiene derecho a la libertad y a la seguridad, y que nadie puede ser privado de su libertad, sino con la observancia de lo establecido en el citado precepto y en los casos y en la forma que contemple la ley.

El Real Decreto 465/2020 modifica el artículo 7.1, primer inciso y letra h, del Real Decreto 463/2020, por cuanto se limita el tránsito de las personas por las vías o espacios públicos para realización de las actividades contempladas, que deberán realizar a título individual, con la excepción de los casos siguientes: acompañamiento a personas con discapacidad, menores, mayores o cualquier otra causa que se justifique.

También se contempla la limitación en el ámbito penitenciario tal y como se indica en la Orden INT/227/2020, ya que se produce la suspensión de las comunicaciones ordinarias de los internos, dado la limitación de la libertad de circulación de ellos mismos como de las familias y personas que les visiten. Quedan suspendidas las salidas de permiso y programas, además de cualquier otra salida, salvo en los casos de fuerza mayor o situación de necesidad, para cumplir con lo indicado en el artículo 7 del Real Decreto 463/2020.

Se discute también la viabilidad de esta situación, ya que estas medidas en realidad están representando una restricción ${ }^{30}$, que no suspensión (recordemos que sólo se pueden dar en una situación de estado de excepción y sitio, pero no de alarma), que se podrían admitir por la situación excepcional y el efecto desplazatorio, pero que serían más que discutibles si las medidas se adoptan para la protección de la salud, que en realidad subyace dicho fundamento para la adopción de las medidas de confinamiento de la población.

b) Medidas adoptadas en el ámbito de la sanidad y la actividad de los profesionales de la salud. Se contemplan las medidas con la finalidad de reforzar el sistema nacional de salud, estableciendo la posibilidad de disponer de servicios extraordinarios por su duración o naturaleza. También en el texto legal se indican medidas para el aseguramiento de suministros de bienes y servicios. Así, se aprobaron la Orden SND/232/2020, que fue modificada por la Orden SND/299/2020, de 27 de marzo, y Orden SND/319/2020, así como la Orden SND/275/2020 y Orden $\mathrm{SND} / 295 / 2020$, modificadas por la Orden SND/322/2020.

30 Sigo la exposición de Cotino (2020b), p. 7 y 8. 
Estas medidas tienen como finalidad el reforzamiento del sistema sanitario en orden a la provisión de la protección de la salud de profesionales al servicio de la sanidad, y evitar un riesgo de contagio por la mayor exposición al virus en el desarrollo de su actividad profesional.

c) Medidas adoptadas para garantizar la salud en el ámbito laboral de los trabajadores. El trabajador tiene que ver tutelado su derecho a la protección de la salud, y es a través del servicio de prevención de riesgos laborales el instrumento idóneo para ello. ${ }^{31}$ Durante el estado de alarma se han regulado las actividades y las medidas para la actividad profesional, y en relación con los medios de transporte. En el ámbito del transporte ferroviario, la Orden TMA/311/2020 contempla la actividad en los centros de mantenimiento permitiendo que realicen las actividades siempre que las mismas dispongan de los medios adecuados para la salvaguarda de la salud y de la seguridad de los trabajadores, y que previamente el Real Decreto $463 / 2020$ ya había contemplado medidas para la limitación de circulación de medios de transporte colectivos (autobús, metro, tren) con la finalidad de preservación de la salud. Véase también la Orden INT/262/2020, modificada por Orden INT/284/2020, Orden APA/288/2020, y las Resoluciones de 20 de marzo de 2020 y 27 de marzo de 2020.

Como indica la Orden INT/226/2020, las medidas que se contemplan en la misma se aplicarán de conformidad con los principios de proporcionalidad y necesidad, y están dirigidas a la protección de la salud y seguridad de los ciudadanos y la contención de la progresión de la epidemia. De esta forma, se contiene medidas para la autoprotección y vigilancia de la salud dirigidas a los funcionarios policiales. De esta forma, se adoptarán medidas tanto en los equipos de trabajo para garantizar la seguridad y salud dentro de las funciones que vayan a desempeñar, y con un seguimiento sobre el estado de su salud.

El Real Decreto 465/2020 modifica el título y el apartado 1 del artículo 10 del Real Decreto 463/2020, y se refiere a las "Medidas de contención en el ámbito de la actividad comercial, equipamientos culturales, establecimientos y actividades recreativas, actividades de hostelería y restauración, y otras adicionales", por lo que se produce la suspensión de la apertura al público de locales y establecimientos minoristas de alimentación, bebidas, productos y bienes de primera necesidad, así como establecimientos farmacéuticos, sanitarios, centros o clínicas veterina-

31 Maestre et al. (2017), p. 95. 
rias, ópticas y productos ortopédicos, productos higiénicos, prensa y papelería, combustible para automoción, estancos, equipos tecnológicos y de telecomunicaciones, alimentos para animales de compañía, comercio por internet, telefónico o correspondencia, tintorerías, lavanderías y el ejercicio profesional de la actividad de peluquería a domicilio.

Junto a ello, se indica que también se producirá la suspensión de la actividad a cualquier establecimientos que, a juicio de la autoridad competente, pueda suponer un riesgo de contagio dependiendo de las condiciones en que se desarrolle.

Las medidas, así como los lugares, establecimientos y actividades podrán ser objeto de modificación, ampliación o restricción por parte del Ministro de Sanidad, atendiendo a razones justificadas de salud pública. ${ }^{32}$

Hay que tener en cuenta que el cierre de determinados establecimientos tal y como indica el artículo 10 del Real Decreto 463/2020 modificado por el Real Decreto 465/2020, no es de carácter exhaustivo ni se establece una enumeración considerada como numerus clausus. Es precisamente la posibilidad de habilitación al Ministro de Sanidad de poder ampliar, modificar o restringir tal y como indica la Orden SND/257/2020, para incluir los alojamientos turísticos, dado que existe el compartir espacios comunes con un riesgo de contagio, por lo que se suspende su apertura al público por dicho motivo. Ello incluye todos los hoteles y alojamientos similares, alojamientos turísticos y otros alojamientos de corta estancia, campings, aparcamientos de caravanas y establecimientos similares situados en territorio español.

Se exceptúa la prestación de los servicios de vigilancia, seguridad y mantenimiento de los mismos, y también se contempla la excepción de los alojamientos turísticos que en el momento de la declaración del estado de alarma, se encuentren hospedados de forma estable y de temporada, siempre que sus ocupantes dispongan de infraestructuras adecuadas para cumplir con lo indicado en el Real Decreto 463/2020. Queda prohibida la admisión de nuevos clientes hasta que no finalice la suspensión contemplada en el estado de alarma.

Para otros ámbitos laborales, como el marítimo, funcionarios, entre otros, hay que atender a lo indicado en la Orden TMA/258/2020, modificada por Orden TMA/309/2020, en la Orden SND/261/2000.

32 Más ampliamente se puede consultar: Gómez (2020), p. 19 y sigs.; Martín (2020), p. 297; Moreno (2020), p. 62. 
En el ámbito foral y autonómico, hay que atender a lo indicado en el Decreto-ley 1/2020, respecto a la Comunidad Autónoma de Extremadura, y el Decreto-ley Foral 1/2020, para la Comunidad Foral de Navarra.

Para garantizar el derecho a la información que se regula en la Ley 17/2015, la Orden INT/228/2020, y la obligación de los medios de comunicación contenida en el artículo 19 del Real Decreto 463/2020 se establecen la inserción de mensajes, anuncios y comunicaciones que se comunicarán de forma previa al Centro Nacional de Seguimiento y Coordinación de Emergencias (CENEM).También en relación con la protección de la salud, se plantea la cuestión de si el derecho a la protección de la salud y las medidas adoptadas de forma preventiva han sido adecuadas. Y, en caso contrario, si se puede exigir la responsabilidad extracontractual o aquiliana que establece el artículo 1902 del Código civil español, por actos que hayan puesto en riesgo el derecho a la protección de la salud de los ciudadanos, y que puedan haber propiciado la expansión exponencial de la pandemia. ${ }^{33}$ Así también por la comercialización de productos de prevención de contagio, por ejemplo, mascarillas que no cumplían con los estándares de calidad marcados por la normativa. ${ }^{34} \mathrm{O}$ la utilización de las nuevas tecnologías de la información y de la comunicación (TICs), por ejemplo para salvaguardar la salud, entre las que podemos mencionar la utilización de aplicaciones móviles para el control de la epidemia, lo que se ha denominado Big Data means big responsability.35 E incluso en las denominadas "altas forzosas" que se han realizado en contra de la voluntad de los pacientes, por falta de recursos en los centros médicos para poder disponer de camas para todos los afectados ${ }^{36}$. En este caso queda palpable la insuficiencia sanitaria, al carecer el sistema de salud de poder ofrecer una respuesta a la necesidad derivada del número creciente de contagios en el escenario del COVID-19. ${ }^{37}$ En cuanto a la obligación de información que se debía facilitar respecto de los productos a los que hace referencia la Orden SND/233/2020 por parte de personas jurídicas que tengan como actividad la fabricación y/o importación de

33 Cfr.PAChot (2010), p. 19. Wunder (2014), p. 287.

34 LÓPEZ (2020), p. 5.

35 Simó (2020), p. 795, que precisa la necesidad de que se realicen las actuaciones de forma transparencia, con información clara, sencilla y comprensible teniendo en cuenta la privacidad y la normativa de protección de datos de carácter personal, respecto a su finalidad. Véase también sobre ello: ANDREU (2020), p. 848;

Cotino (2020c), p. 1 y sigs.

36 Moreno (2020), p. 571.

37 Sobre la suficiencia sanitaria, resulta de interés la aportación de MARTínez et al. (2020), pp. 140 y sigs. 
los productos señalados en la citada Orden. La no presentación de dicha información, así como la falsedad, se considerará infracción administrativa en materia de salud pública susceptible de sanción de conformidad con la Ley 33/2011.

\section{Los colectivos vulnerables ante las medidas adoptadas en el estado de alarma para la protección de la salud}

Vamos a centrarnos en las medidas de protección adoptadas para los colectivos más vulnerables. El Real Decreto 463/2020, en la adopción de medidas, se refería a colectivos vulnerables, pero, en ningún momento, indica qué personas estarían incluidas..$^{38}$ Esta medidas que aparecen reguladas en las normas aprobados en la situación de pandemia, y también en otras normas de salud que son aplicables de forma supletoria, tienen que atender a los derechos humanos como la no discriminación por edad, sexo, o tipo de enfermedad que lleva consigo el respeto a la dignidad de la persona ${ }^{39}$. No siempre se ha cumplido esta premisa, ya que muchas de las medidas no han atendido a las personas más vulnerables, como ha sido el caso de los ancianos, que han resultado afectados por la pandemia ${ }^{40}$, siendo la mayoría de sus víctimas.

Uno de los colectivos especialmente vulnerables ${ }^{41}$ en la sociedad son las personas víctimas de violencia de género. Esta violencia no sólo se centra en la mujer, sino también en los menores que están aislados con ellos. ${ }^{42}$

Las medidas adoptadas por el Gobierno durante el estado de alarma ${ }^{43}$ han supuesto para este colectivo una situación altamente crítica y es por ello, que, en un principio no se contemplaron medidas específicas en el Real Decreto 463/2020, pero sí en posterior Real Decreto-ley 12/2020, que considera que el confinamiento o aislamiento domiciliario y la convivencia con el agresor, constituye una situación de riesgo. Hay que tener en cuenta que como colectivo especialmente vulnerable se establece una protección no sólo nacional, sino internacional. Así, podemos referirnos a la Ley Orgánica 1/2004; Ley Orgánica 5/2018; Real Decreto-ley 9/2018 y Ley 3/2019, y también al Convenio del Consejo de Europa sobre

38 Presno (2020), p. 56.

39 PÉrez (2020), p. 128.

40 Proporcionan datos referentes a estos colectivos el estudio de AQuino et al. (2020), pp. 16 y sigs.

41 Véase: Presno (2020), p. 56.

42 RAMÓN (2013), p- 6o; (2018), p. 50; (2019), p. 18.

43 Cfr. Baelo y Díaz-Bautista (2020a), p. 5; (2020b), p. 3. 
prevención y lucha contra la violencia contra la mujer y la violencia doméstica, hecho en Estambul, el 11 de mayo de 2011, y ratificado por España.

Las medidas se traducen en la declaración de servicio esencial; el funcionamiento de los servicios durante las 24 horas referentes a la información y asesoramiento jurídico, teleasistencia y asistencia social; servicios de acogida a las víctimas; establecimiento a través de las tecnologías de la información y comunicación (TICs) de medios telemáticos del cumplimiento de medidas cautelares y órdenes de alejamiento para garantizar la seguridad de las víctimas, y medidas referentes al personal que presta servicios de asistencia social integral a las mismas, adaptándose a la falta de presencialidad. ${ }^{44}$

Por último, indicar las medidas adoptadas para la protección de uso personal en relación a la protección de la salud por el Real Decreto-ley 21/2020 respecto al uso obligatorio de las mascarillas, como equipo de protección individual, tal y como estableció la Orden SND/354/2020.

\section{Reflexión sobre la oportunidad de las medidas adoptadas en la crisis sanitaria por la COVID-19 en relación con el derecho a la vida y a la protección de la salud}

Nos planteamos si las medidas adoptadas durante la crisis sanitaria han contemplado y no han infringido el derecho a la vida y a la protección de la salud. Una de las consecuencias que se ha producido durante la pandemia ha sido el alto número de fallecimientos. Un gran número ha sido de personas de avanzada edad y colectivos vulnerables. Los motivos, entre otros, han sido la falta de una atención médica y sanitaria por el colapso de los servicios hospitalarios. ${ }^{45}$ Ello se pone en relación con el derecho a la vida, ya que esa falta de asistencia derivada de una gestión deficitaria de los recursos públicos determina que haya habido una selección de los individuos a la hora de acceder al tratamiento y a la hospitalización.

44 Véase: Magro (2020).

45 Como pone de relieve Rotondo (2020), p. 156 y 157, refiriéndose a Italia, también azotada por la pandemia: "En el aspecto sanitario la pandemia derivada del SARS-CoV-2 tiene tintes dramáticos. En Italia, desde los primeros días de su difusión, se ha puesto de manifiesto la inadecuación del sistema de salud nacional para reaccionar frente a la repentina difusión del virus entre la población. El insuficiente número de dotaciones técnicas (dispositivos de protección individual, hospitales, camas y respiradores artificiales) y la escasez de personal sanitario para afrontar el extraordinario número de enfermos han sido los principales problemas con los cuales han tenido que lidiar los encargados de gestionar la emergencia sanitaria” 
Hemos analizado en los puntos anteriores la regulación, así como el contenido del derecho a la vida y a la protección de la salud en la legislación española.

Pero estos derechos, como además indica muy acertadamente la doctrina ${ }^{46}$, no sólo se contemplan a nivel nacional, sino también a nivel supranacional, como es el artículo 2 del Convenio Europeo de Derechos Humanos que contempla el derecho a la vida. ${ }^{47}$

Por su parte, la Carta Social Europea, en su artículo 2, recoge el derecho a la protección de la salud..$^{8}$

Ante dicha situación, se plantea si las medidas tomadas fueron oportunas, teniendo en cuenta que en muchos casos se consideró el no ingreso de ciertas personas dada su vulnerabilidad y ante la escasez de medios sanitarios suficientes para todos realizar una criba, lo que se denomina el triaje y no acceder a poder ser atendido en los centros o no proporcionales todos los medios médicos suficientes para la salvación de la persona. ${ }^{49}$ Esta circunstancia ha derivado en la exigencia

46 MARTínez (2020), p. 2.

47 Este precepto establece que: "1. El derecho de toda persona a la vida está protegido por la ley. Nadie podrá ser privado de su vida intencionadamente, salvo en ejecución de una condena que imponga la pena capital dictada por un Tribunal al reo de un delito para el que la ley establece esa pena.

2. La muerte no se considerará como infligida en infracción del presente artículo cuando se produzca como consecuencia de un recurso a la fuerza que sea absolutamente necesario:

a) en defensa de una persona contra una agresión ilegítima;

b) para detener a una persona conforme a derecho o para impedir la evasión de un preso o detenido legalmente ;

c) para reprimir, de acuerdo con la ley, una revuelta o insurrección".

48 Establece el precepto que: "Para garantizar el ejercicio efectivo del derecho a la protección de la salud, las Partes se comprometen a adoptar, directamente o en cooperación con organizaciones públicas o privadas, medidas adecuadas para, entre otros fines:

1. Eliminar, en lo posible, las causas de una salud deficiente;

2. Establecer servicios formativos y de consulta dirigidos a la mejora de la salud y a estimular el sentido de responsabilidad individual en lo concerniente a la misma;

3. Prevenir, en lo posible, las enfermedades epidémicas, endémicas y otras, así como los accidentes."

Como expresa Climent (2020), p. 637, "ha sido interpretado por el Comité Europeo de Derechos Sociales (CEDS), como el derecho a gozar del más alto nivel posible de salud. Ello incluye el derecho de acceso equitativo a una atención sanitaria de calidad apropiada. Debemos tener en cuenta que, en todo caso, este derecho a la protección de la salud siempre vendrá limitado por el grado de desarrollo alcanzado por la ciencia en el momento en que pretenda ejercerse".

49 En el caso de Italia, Rotondo (2020), p. 158, se refiere a la Sociedad Italiana de Anestesia, Analgesia, Reanimación y Terapia Intensiva (SIAARTI) y a las "Recomendaciones de Ética Clínica para la admisión de tratamientos intensivos y para su suspensión, en condiciones excepcionales de desequilibrio entre necesidad y recursos disponibles". Y alude a que "Dejando aparte las vagas y genéricas referencias a conceptos como "adecuación clínica», "proporcionalidad de las curas», "justicia distributiva», que, si no se definen, resultan vacios de contenido, parece que el desequilibrio entre las necesidades clínicas de la población y la efectividad de los recursos para los tratamientos intensivos sea resuelto por la Siaarti en clave meramente utilitarista. 
de responsabilidades ante las medidas adoptadas que fueron discriminatorias en relación al derecho a la vida y a la protección de la salud.

La doctrina para dar respuesta a esta cuestión de la oportunidad o no de las medidas adoptadas, ha considerado oportuno traer a colación la jurisprudencia del Tribunal Europeo de Derechos Humanos para establecer el alcance y delimitación de los derechos en juego..$^{\circ}$

En este sentido, la jurisprudencia se orienta en la responsabilidad médica por incumplimiento de la lex artis, y también en la delimitación de la obligación estatal de garantizar el derecho a la vida en el entorno médico. Así, la sentencia Lopes de Sousa Fernandes contra Portugal (Gran Sala), de 19 de diciembre de 2017. ${ }^{51}$ Como señala Martínez ${ }^{52}$ "Esta norma no solo impone a los Estados la obligación de abstenerse de dar muerte de forma intencional, sino también la obligación de adoptar todas las medidas necesarias para la protección de la vida de las personas en su jurisdicción ( $\$ 164$ Lopes de Sousa). Y así, aunque el derecho a la salud no aparezca expresamente mencionado en el Convenio, esta obligación del Estado debe interpretarse como existente en toda actividad, pública o no, susceptible cde afectar al derecho a la vida ( $\$ 165$ Lopes de Sousa)".

Siguiendo esta jurisprudencia y la normativa supranacional, el derecho a la vida, en su aspecto sustantivo, implicaría una obligación estatal de establecer una regulación que obligara a los hospitales a adoptar medidas para proteger la vida de las personas..$^{53} \mathrm{Y}$, en todo caso, determinar si la regulación actual es suficiente para garantizar los derechos constitucionales.

Pero, nos podemos plantear si las medidas adoptadas y que hemos referido en un punto anterior del presente trabajo han sido adecuadas o no, es decir, su oportunidad, y si hubiera sido conveniente adoptar otras o incluso incrementar las adoptadas con otras complementarias. El número de fallecimientos no determina una violación del derecho a la vida, sino si ese número de fallecimientos es debido

En el documento, de hecho, se dice que, en un contexto de carencia de recursos sanitarios, la elección debe ir orientada en favor de garantizar los tratamientos que tengan «mayor posibilidad de éxito terapéutico», privilegiando la «mayor esperanza de vida», basándose en la consideración del «first come first served». En particular, en la Recomendación núm. 3, se explicita la posibilidad de poner un límite de edad para los ingresos y en la núm. 4 que la presencia de enfermedades añadidas a la edad, potencialmente, puede dar lugar a un mayor consumo de recursos en el caso de pacientes ancianos, frágiles o con enfermedades severas".

50 Sigo la exposición de Martínez (2020), p. 2 y sigs.

51 Citada por Martínez (2020), p. 2.

52 Martínez (2020), p. 2.

53 Martínez (2020), p. 2. 
a la no adopción de medidas de protección adecuadas o si se han cumplido las exigencias establecidas en las normas ${ }^{54}$ con lo que no se establecería una relación de causalidad.

Se trata de determinar si las medidas adoptadas eran oportunas para garantizar el derecho a la vida y a la protección de la salud. Ahí entraría en juego la consideración de si los colectivos vulnerables, en especial las personas de mayor edad y las que se encontraban en residencias se les limitó el acceso a los recursos sanitarios y se estaba produciendo una vulneración del derecho a la vida. La jurisprudencia que hemos referido indicaba que "hay violación del derecho a la vida cuando se pone en riesgo la vida de una persona al denegarle los cuidados médicos que las autoridades sanitarias se ha comprometido a proporcionar al conjunto de la población ( $\$ 173$ Lopes de Sousa)".55

La responsabilidad en el ámbito del Convenio Europeo de Derechos Humanos se contempla en los supuestos en que no se tiene acceso a los recursos sanitarios por un deficiente funcionamiento del sistema, y cuando se conocía el riesgo y no se adoptaron las medidas oportunas para evitarlo, con el riesgo para la vida. ${ }^{56}$

En el caso de la pandemia, la medida adoptada de no ingresar a determinados pacientes por la falta de recursos hospitalarios podría dilucidarse si era oportuna o no o si se consideraba una medida excepcional ante un supuesto de fuerza mayor, pero también se pone en tela de juicio la normativa aplicable al ámbito sanitario y su eficacia ante una situación como la vivida. Hay que tener en cuenta que el artículo 41 del texto constitucional determina que: "Los poderes públicos mantendrán un régimen público de Seguridad Social para todos los ciudadanos que garantice la asistencia y prestaciones sociales suficientes ante situaciones de nece-

54 Señala MARTínez (2020), p. 3, que "No obstante, y aunque normalmente no se han apreciado insuficiencias en el marco regulatorio, el asunto Arskaya contra Ucrania (Sección Tercera) de 5 de diciembre de 2013 es uno de los pocos casos en que el TEDH ha apreciado que el marco legal no era adecuado para proteger el derecho a la vida y se aprecia en consecuencia violación del aspecto sustantivo de este derecho. Rara vez el TEDH ha apreciado deficiencias en el marco regulatorio".

55 Martínez (2020), p. 4.

56 Martínez (2020), p. 5. Añade que: "El TEDH sistematiza tres requisitos que deben concurrir para apreciar violación del derecho a la vida por parte de un Estado en el ámbito sanitario (\$\$194 a 196 Lopes de Sousa). En primer lugar, que a pesar de sus obligaciones profesionales, los sanitarios hayan negado a un paciente un tratamiento médico de urgencia cuando sabían que con ello pondrían en riesgo la vida del paciente. En segundo lugar, para que se pueda atribuir a las autoridades del Estado, el mal funcionamiento debe ser reconocible objetiva y realmente como sistémico o estructural y no debe comprender únicamente el caso individual en el que algo no haya funcionado o haya funcionado mal. Y en tercer lugar debe haber una relación entre el mal funcionamiento denunciado y el perjuicio sufrido por el paciente, al haberse debido a que el Estado no haya respetado su obligación de establecer un marco reglamentario comprendido en sentido amplio". 
sidad". ${ }^{7}$ Y la Ley 14/1986, en su artículo 1 preceptúa que dicha norma tiene como objeto "la regulación general de todas las acciones que permitan hacer efectivo el derecho a la protección de la salud reconocido en el artículo 43 y concordantes de la Constitución". Su artículo 10, que delimita los derechos de los pacientes, indica en su apartado 1 que "todos tienen los siguientes derechos con respecto a las distintas administraciones públicas sanitarias: 1 . Al respeto a su personalidad, dignidad humana e intimidad, sin que pueda ser discriminado por razones de raza, de tipo social, de sexo, moral, económico, ideológico, político o sindical”.

La Ley Orgánica 3/1986, a la que nos hemos referido anteriormente, indica en sus preceptos que para la protección de la salud pública y prevenir su pérdida o deterioro, las autoridades sanitarias podrán adoptar las medidas que contempla esta norma en los casos que lo exijan razones sanitarias de urgencia o necesidad. Estas medidas se refieren a reconocimiento, tratamiento, hospitalización o control en los casos en que se aprecien indicios racionales que permitan suponer la existencia de peligro para la salud de la población debido a la situación sanitaria concreta de una persona o grupo o por las condiciones sanitarias en que se desarrolle una actividad. Para el control de enfermedades transmisibles, se podrán además de realizar acciones preventivas generales, adoptar medidas oportunas para el control de los enfermos, de las personas que se encuentren o hayan tenido contacto, así como las que se consideren necesarias en el caso de riesgo de carácter transmisible. ${ }^{8}$

Esa legislación ha sido capaz de dar respuesta a la necesidad social?59 Sería esta la cuestión que nos podemos plantear y que cabe relacionar con una vulneración del derecho a la vida y a la protección de la salud, ya que las personas que no accedieron a los centros sanitarios por el colapso sufrieron una discriminación frente a las que sí que pudieron acceder. ${ }^{6}$

Consideramos que las medidas adoptadas no fueron oportunas y la discriminación en el acceso a los recursos sanitarios fue motivada por una normativa no

57 Alventosa (2020), p. 111.

58 Cfr. Ruiz (2020), p. 3 y sigs.

59 Como advierte Alventosa (2020), p. 114, "Sin embargo, este marco normativo que es de aplicación a las situaciones ordinarias de la vida cotidiana sufre una alteración cuando existe peligro para la salud pública, e inclusive para el propio paciente. Como es la situación que vivimos en España y en el mundo por la enfermedad del COVID-19 (...) El Estado de alarma ha tenido incidencia directa en el ámbito sanitario. Además de las dificultades técnicas, de medios y de personal que ha sufrido el sistema sanitario español por la expansión de la pandemia, éste también se ha visto alterado en cuanto a sus parámetros jurídicos".

6o Martínez (2020), p. 5. 
eficiente en la distribución de los mismos, con lo que se establecería una vulneración del precepto referido del Convenio Europeo de Derechos Humanos. ${ }^{61}$ Esperemos que en un futuro se realicen cambios normativos necesarios para evitar que la legislación no sea suficiente para cumplir con las expectativas sociales. ${ }^{62}$

\section{Conclusiones}

En el presente trabajo nos hemos ocupado de reflexionar sobre el derecho a la protección de la salud en relación con el estado de alarma declarado en España por la pandemia del coronavirus, declarado por el Real Decreto 463/2020, y sucesivamente prorrogado en diversas ocasiones.

Este estado de alarma se ha discutido si en realidad no ha supuesto un estado de excepción bajo el ropaje del estado anterior, y si ha habido una suspensión de los derechos contemplados en el artículo 55 de la Constitución española, y no una supresión o restricción de los mismos.

La situación de crisis sanitaria ha supuesto una amenaza para la salud de los ciudadanos y que justificaba que se estableciera una restricción de derechos de la ciudadanía como era la limitación del movimiento, al establecerse un aislamiento de la población o cuarentena durante el estado de alarma. En estos momentos, nos encontramos todavía en dicho estado, pero con una flexibilización de la libertad de movimiento, que ha ido reestableciendo lo que se va a denominar "nueva normalidad". Son numerosas las cuestiones que se plantean sobre el derecho a la protección de la salud y la implicación sobre otros derechos fundamentales, como es el caso del derecho a la vida, y una de ellas es si ese derecho a la protección de la salud que contempla la Constitución española debe ser considerado como un derecho exigible a mantener la vida o si se considera como un derecho a la protección de la salud, pero no de la salud, de estar sano, sino de establecer los medios de protección y no un derecho absoluto a no enfermar. Es por ello que las medidas voluntarias de aislamiento han sido adoptadas por la población para evitar el contagio y hubiera sido deseable la creación de unidades de salud global como ha apuntado la doctrina. ${ }^{63}$

61 En el mismo sentido, Martínez (2020), p. 5.

62 Martínez (2020), p. 25.

63 Pérez-Then (2020), p. 7. 
Las interpretaciones doctrinales diferencian entre el derecho a la salud, el derecho a la protección de la salud y el derecho a la vida. La exigencia o no de responsabilidad tanto de tipo administrativo, civil como penal no es una cuestión baladí, y de hecho se han iniciado distintos procedimientos judiciales en base a la responsabilidad estatal por determinados actos que han puesto en riesgo la protección de la salud del ciudadano. ${ }^{64}$

De igual modo, la situación de emergencia sanitaria y la escasez de recursos disponibles para atender a las personas afectadas ha generado un problema en cuanto a la conjunción del derecho a la vida y el derecho a la protección de la salud, ya que se ha limitado el acceso a los recursos, y con ello, una limitación del derecho a la vida para las personas dependiendo de distintas circunstancias como edad, estado de salud, comorbilidad y esperanza de vida. Tenemos que tener en cuenta que estamos en sede de derechos humanos, la vida no puede ser objeto de discriminación, y más aún en el caso de los ancianos, verdaderas víctimas de la pandemia, ya que se debe incrementar los recursos y su disponibilidad antes de priorizar la utilización de los mismos a unas personas en detrimento de otras, ya que ello supone la limitación y restricción de un derecho fundamental.

Se refiere la doctrina a la denominada ponderación de derechos ${ }^{65}$ ya que hay que determinar el interés asignado, y el grado de satisfacción de cualquier otro que se encuentre dentro de los derechos fundamentales para justificar la lesión. Este argumento nos sirve para determinar si las medidas adoptadas han sido oportunas o no teniendo en cuenta el derecho a la vida y la protección de la salud. La respuesta sobre la oportunidad se tiene que encontrar en la aplicación de las directrices internacionales, así como en la jurisprudencia analizada del Tribunal Europeo de Derechos Humanos.

La proliferación de normas aprobadas por el Gobierno tampoco han resultado completas, ya que se detectan lagunas en su interpretación, así como la ausencia de concreción de las distintas medidas a adoptar en la crisis sanitaria por la pandemia. Ello ha supuesto la aprobación posterior de normas complementarias para poder cubrir la afectación de todos los sectores, principalmente los sujetos más vulnerables afectados por el COVID-19.

Junto a ello, nos hemos encontrado con una proliferación de normas elaboradas por el Gobierno que no resultan del todo completas, ya que se encuentran

64 Véase DomÉnech (2020), p. 103.

65 Alvarado (2015), p. 411. 
lagunas en su interpretación, así como la ausencia, en un principio, de concreción de las distintas medidas a adoptar en la situación de pandemia, que se han visto complementadas por otras normas posteriores para poder cubrir la afectación de todos los sectores tanto económicos como sociales que se ven afectados por la crisis del COVID-19, teniendo en cuenta los sujetos más vulnerables.

Consideramos, por último, que en este caso de pandemia hubiera sido adecuado la adopción de un principio precautorio ${ }^{66}$, que no es lo mismo que preventivo, desde que se tuvo conocimiento del inicio de casos en España, y hubiera paliado la adopción de medidas tan restrictivas para los derechos de la población.

\section{Bibliografía citada}

Alegre Martínez, Miguel Ángel (2004): "Los derechos sociales en la Carta de los Derechos Fundamentales de la Unión Europea”, en A.A.V.V., Escritos sobre el derecho europeo de los derechos sociales (Valencia, Editorial Tirant lo Blanch) pp. 63-111.

Allard Soto, Raúl, Henning Leal, Mônia C. y Galdámez Zelada, Liliana (2016): "El derecho a la salud y su (des) protección en el estado subsidiario", en Estudios Constitucionales (Vol. 14, No 1), pp. 95-138. Disponible en: https:// scielo.conicyt.cl/pdf/estconst/v14n1/arto4.pdf [fecha de consulta: 05 de abril de 2020].

Alpuche Aranda, Celia M. (2020): "Infecciones emergentes, el gran reto de la salud global: Covid-19”, en Salud pública de México (Vol. 62, № 2), pp. 123-124. Disponible en: http://saludpublica.mx/index.php/spm/article/ view/11284/11845 [fecha de consulta: 02 de abril de 2020].

Alvarado marambio, José Tomás (2015): "Derechos fundamentales, interpretación proporcionalista y consecuencialismo. La relevancia jurídica de las teorías morales fundamentales", en Estudios Constitucionales (Vol. 13, № 2), pp. 391420. Disponible en: http://www.estudiosconstitucionales.cl/index.php/econstitucionales/article/view/292/271 [fecha de consulta: 04 de abril de 2020].

Álvarez García, Vicente J. (2020): "El coronavirus (COVID-19): respuestas jurídicas frente a una situación de emergencia sanitaria", en El Cronista del Estado Social y Democrático de Derecho (No 86-87) pp. 6-21. Disponible en:

66 VALERIO (2020), p. 441. 
http://www.elcronista.es/El-Cronista-n\%C3\%BAmero-86-87-Coronavirus.pdf [fecha de consulta: 30 de marzo de 2020].

Alventosa Del Río, Josefina (2020): "Salud y Derecho en tiempo del COVID-19", en Actualidad Jurídica Iberoamericana (No Extra 12,2), pp. 108-117. Disponible en: http://www.revista-aji.com/wp-content/uploads/2020/05/11._Josefina_Alventosa_pp._108-117.pdf [fecha de consulta: 29 de julio de 2020].

Andreu Martínez, Belén (2020): "Privacidad, geolocalización y aplicaciones de rastreo de contactos en la estrategia de salud pública generada por la COVID-19", en Actualidad Jurídica Iberoamericana (No Extra 12, 2), pp. 848-859. Disponible en: http://www.revista-aji.com/wp-content/uploads/2020/05/78. Belén_Andreu_pp._848-859.pdf [fecha de consulta: 29 de julio de 2020].

Aquino Canchari, Christian Renzo, Quispe Arrieta, Rocío del Carmen y Huaman Castillon, Katia Medalith (2020): "COVID-19 y su relación con poblaciones vulnerables”, en Revista Habanera de Ciencias Médicas (Vol. 19, No Extra o), pp. 1-18. Disponible en: http://www.revhabanera.sld.cu/index.php/ rhab/article/view/3341/2537 [fecha de consulta: 12 de junio de 2020].

Carbonell SÁnchez, Miguel (2008): "Eficacia de la Constitución y derechos sociales: esbozo de algunos problemas", en Estudios Constitucionales, (Vol. 6, No 2), pp. 43-72. Disponible en: http://www.estudiosconstitucionales.cl/index. php/econstitucionales/article/view/255/243 [fecha de consulta: 05 de abril de 2020].

Climent Gallart, Jorge Antonio (2020): "El Consejo de Europa y el COVID-19 (coronavirus)", en Actualidad Jurídica Iberoamericana ( $\mathrm{N}^{\circ}$ Extra 12,2), pp. 634-645. Disponible en: http://www.revista-aji.com/wp-content/ uploads/2020/05/59._Jorge_Antonio_Climent_pp._634-645.pdf $[\mathrm{fecha}$ de consulta: 29 de julio de 2020 ].

Cotino Hueso, Lorenzo (2020a): “Confinamientos, libertad de circulación y personal, prohibición de reuniones y actividades y otras restricciones de derechos por la pandemia del Coronavirus", en Diario La Ley (No 9606), pp. 1-20. -(2020b): "Los derechos fundamentales en tiempos del coronavirus: Régimen general y garantías y especial atención a las restricciones de excepcionalidad ordinaria”, en El Cronista del Estado Social y Democrático de Derecho (No 8687) pp. 88-101. Disponible en: http://www.elcronista.es/El-Cronista-n\%C3\%BAmero-86-87-Coronavirus.pdf [fecha de consulta: 03 de abril de 2020]. 
-(2020c): "Inteligencia artificial, big data y aplicaciones contra la COVID-19: privacidad y protección de datos", en IDP. Revista de Internet, Derecho y Política (No 31), pp. 1-17. Disponible en: https://idp.uoc.edu/articles/abstract/10.7238/ idp.voi31.3244/ [fecha de consulta: 29 de julio de 2020].

Doménech Pascual, Gabriel (2020): "Responsabilidad patrimonial del Estado por la gestión de la crisis del COVID-19”, El Cronista del Estado Social y Democrático de Derecho (№ 86-87) pp. 102-109. Disponible en: http://www.elcronista.es/El-Cronista-n\%C3\%BAmero-86-87-Coronavirus.pdf [fecha de consulta: O3 de abril de 2020].

Ferrer Mac-Gregor, Eduardo y Pelayo Müller, Carlos M. (2012): "La obligación de «respetar» $\mathrm{y}$ "garantizar» los derechos humanos a la luz de la jurisprudencia de la Corte Interamericana. Análisis del artículo 1 del Pacto de San José como fuente convencional del derecho procesal constitucional mexicano", en Estudios Constitucionales, (Vol. 10, No 2), pp. 141-192. Disponible en: http://www.estudiosconstitucionales.cl/index.php/econstitucionales/article/ view/80/75 [fecha de consulta: 05 de abril de 2020].

Figueroa García-Huidobro, Rodolfo (2013): "Derecho a la salud", en Estudios Constitucionales, (Vol. 16, № 2), pp. 283-332. Disponible en: http://www.estudiosconstitucionales.cl/index.php/econstitucionales/article/view/39/35 [fecha de consulta: 05 de abril de 2020].

Gómez Zamora, Leopoldo J. (2020): "Breve estudio de las medidas adoptadas durante el estado de alarma para la gestión de la situación de crisis sanitaria ocasionada por el covid-19", en Gabilex: Revista del Gabinete Jurídico de Castilla-La Mancha (No Extra 21), pp. 19-72. Disponible en: https://gabilex.castillalamancha.es/sites/gabilex.castillalamancha.es/files/pdfs/articulo_leopoldo.pdf [fecha de consulta: 29 de julio de 2020 ].

Hamulák, Ondrej, Troitiño, David Ramiro y Chochia, Archil (2018): “La Carta de los Derechos Fundamentales de la Unión Europea y los Derechos Sociales", en Estudios Constitucionales (Vol. 16, № 1), pp. 167-186. Disponible en: http://www.estudiosconstitucionales.cl/index.php/econstitucionales/article/ view/437/342 [fecha de consulta: 04 de abril de 2020].

KNIGHT soto, Idarmis (2015). "La protección al derecho a la vida e integridad física del niño, niña y adolescente como respeto a la dignidad humana”, en Letras jurídicas: revista de los investigadores del Instituto de Investigaciones Jurídicas 
U. V. (No 31), pp. 95-108. Disponible en: http://letrasjuridicas.com.mx/Volumenes/31/Ao6.pdf [fecha de consulta: 29 de julio de 2020].

Lizaraso Caparó, Frank y Del Carmen SARa, José (2020): “Coronavirus y las amenazas a la salud mundial”, en Horizonte médico (Vol. 2, № 1), pp. 4-5. Disponible en: http://www.horizontemedico.usmp.edu.pe/index.php/horizonte$\mathrm{med} / \mathrm{article} / \mathrm{view} / 1193 / 696$ [fecha de consulta: 29 de julio de 2020].

López LluCH, Guillermo (2020): "El SARS-CoV-2 y la COVID-19. Los peligros de una humanidad hacinada", en MoleQla: revista de Ciencias de la Universidad Pablo de Olavide (No 37), pp. 5-11. Disponible en: https://www.upo.es/cms1/ export/sites/upo/moleqla/documentos/Numero37/Numero-37.pdf [fecha de consulta: o1 de abril de 2020].

López Fraile, Luis (2020): “Consideraciones jurídicas sobre la distribución de mascarillas «fake» en el contexto de la Covid-19, en Diario La Ley (No 9651), pp. 1-13.

Maestre Naranjo, María Ascensión, Dietl Sagües, Margarita, Olivares Román, Sahilyn, García Arcones, Raquel, Gómez Grego, Rocío y Rodríguez de la Pinta, María Luisa (2017): "Actuación de un servicio de prevención de riesgos laborales para la atención a casos sospechosos de enfermedad respiratorio por coronavirus (MERS-CoV): A propósito de un caso", en Medicina y seguridad del trabajo ( $\mathrm{N}^{\circ}$ 247), pp. 93-102. Disponible en: http://scielo.isciii.es/pdf/mesetra/v63n247/0465-546X-mesetra-63-247-00093.pdf [fecha de consulta: 01 de abril de 2020].

Magro Servet, Vicente (2020): "Casuística sobre la violencia de género y la declaración del estado de alarma a raíz del Coronavirus", en Diario La Ley (No 9601).

Marazuela, Enrique (2020): "El impacto del coronavirus", en Inversión: el semanario líder de bolsa, economía y gestión de patrimonios ( $\mathrm{N}^{\circ}$ 1175), p. 56.

Martín Lorenzo, Beatriz (2020): "Medidas de protección a las personas mayores durante la crisis sanitaria ocasionada por el covid-19”, en Gabilex: Revista del Gabinete Jurídico de Castilla-La Mancha (No Extra 21), pp. 287-318. Disponible en: https:/gabilex.castillalamancha.es/sites/gabilex.castillalamancha.es/ files/pdfs/articulo_beatriz_martin.pdf [fecha de consulta: 29 de julio de 2020].

Martínez Escribano, Celia (2020): "El derecho a la vida ante la crisis sanitaria provocada por la Covid-19”, en La Ley (No 9663), pp.1-6. Disponible en: https:// 
diariolaley.laleynext.es/dll/2020/o6/29/el-derecho-a-la-vida-ante-la-crisis-sanitaria-provocada-por-la-covid-19 [fecha de consulta: 29 de julio de 2020].

Martínez Moquerza, Javier, Perelló Oliver, Salvador, Martín de Diego, Isaac, Aceña, Víctor, Cuesta, Marina, Lancho, Carmen y González Fernández, César (2020): "Suficiencia sanitaria y COVID-19", en Methaodos: revista de ciencias sociales (Vol. 8, No 1), pp. 140-168. Disponible en: https://www.methaodos.org/revista-methaodos/index.php/methaodos/article/ view/349/499 [fecha de consulta: 12 de junio de 2020].

Martínez Olmos, José (2020): "Políticas sanitarias públicas para después de la crisis del coronavirus", en Temas para el debate (No 305-306), pp. 25-27.

Moreno, Óscar (2020): "Foro de Salud Conectada: Coronavirus: enfoque de la UE de aplicaciones eficientes de rastreo de contactos para contribuir a la supresión gradual de las medidas de confinamiento", en I+S: Revista de la Sociedad Española de Informática y Salud (No 139), pp. 62-63. Disponible en: https://seis.es/is-139-abril-2020/ [fecha de consulta: 29 de julio de 2020].

Moreno Jiménez, Abelardo (2020): "Las altas hospitalarias forzosas a domicilio «vs» derechos del paciente ante la situación del Covid 19", en Actualidad del derecho sanitario ( $\mathrm{N}^{\circ} 281$ ), pp. 570-573.

Nogueira Alcalá, Humberto (2005): “Aspectos de una teoría de los Derechos Fundamentales: La delimitación, regulación, garantías y limitaciones de los Derechos Fundamentales", en Ius et Praxis (Vol. 11, No 2), pp. 15-64. Disponible en: https://scielo.conicyt.cl/scielo.php?script=sci_arttext\&pid=So718-00122005000200002\&lng=en\&nrm=iso\&tlng=es $[$ fecha de consulta: 05 de abril de 2020].

Nogueira López, Alba (2020): "Confinar el coronavirus: Entre el viejo Derecho sectorial y el Derecho de excepción”, en El Cronista del Estado Social y Democrático de Derecho (No 86-87) pp. 22-31. Disponible en: http://www.elcronista. es/El-Cronista-n\%C3\%BAmero-86-87-Coronavirus.pdf [fecha de consulta: 30 de marzo de 2020].

Organización Mundial de la Salud (2020): Disponible en: https://www.who. int/es [fecha de consulta: 15 de marzo de 2020].

Paснот Zambrana, Karel Luis (2010): “A propósito del carácter fundamental de los Derechos económicos, sociales y culturales. Una mirada desde la doctrina comparada y la experiencia del ordenamiento Jurídico Cubano", en Estudios Constitucionales (Vol. 8, № 1), pp. 13-42. Disponible en: http://www.estudios- 
constitucionales.cl/index.php/econstitucionales/article/view/203 [fecha de consulta: 05 de abril de 2020].

Pérez Fuentes, Gisela María (2020): "Pandemia y derecho a la vida y la salud en América y México. Reflexiones a partir de la Resolución 1/2020 de la OEA", en Actualidad Jurídica Iberoamericana (Vol.2, No Extra 12), pp. 126-135. Disponible en: http://www.revista-aji.com/wp-content/uploads/2020/05/13._Gisela_P\%C3\%A9rez_pp._126-135.pdf [fecha de consulta: 12 de junio de 2020].

PÉreZ-Then, Eddy (2020): "Nuevo coronavirus 2019 ncov. Impacto en salud global", en Ciencia y Salud (Vol. 4, No 1), pp. 5-9. Disponible en: https://revistas. intec.edu.do/index.php/cisa/article/view/1672/2219 [fecha de consulta: 12 de junio de 2020].

Piga Rivero, Antonio (2020): "Guías de prevención y respuesta sanitaria ante epidemias y pandemias. Su significación para Covid 19", en Actualidad de derecho sanitario ( $\mathrm{N}^{\circ} 279$ ), pp. 271-276.

Poli, Tommaso N. (2012): "Limitaciones específicas de derechos fundamentales", en Revista de derecho constitucional europeo ( $\left.\mathrm{N}^{\circ} 17\right)$, pp. 305-346.

Presno Linera, Miguel Ángel (2020): "Estado de alarma por coronavirus y protección jurídica de los grupos vulnerables", en El Cronista del Estado Social y Democrático de Derecho (No 86-87) pp. 54-65. Disponible en: http://www. elcronista.es/El-Cronista-n\%C3\%BAmero-86-87-Coronavirus.pdf [fecha de consulta: 30 de marzo de 2020].

RAMÓn FERnÁndeZ, Francisca (2013): "Medidas de protección del menor en los casos de violencia de género", en Reinad. Revista sobre la infancia y la adolescencia ( $\mathrm{N}^{\circ}$ 4), pp. 55-77. Disponible en: http://ojs.upv.es/index.php/reinad/ article/view/1391 [fecha de consulta: 02 de abril de 2020].

-(2018): Menor y violencia de género: Aspectos y retos jurídicos en la sociedad actual (Valencia, Editorial Tirant lo Blanch).

-(2019): "La monoparentalidad derivada de la violencia de género: análisis de la cuestión” en Reinad. Revista sobre la infancia y la adolescencia ( $\left.\mathrm{N}^{\mathrm{o}} 16\right)$, pp. 14-28. Disponible en: https://polipapers.upv.es/index.php/reinad/article/ view/10844/11250 [fecha de consulta: 02 de abril de 2020].

Ramos, Celso (2020): "Covid-19: la nueva enfermedad causada por un coronavirus”, en Salud Pública de México (Vol. 62, № 2), pp. 225-227. Disponible en: http://saludpublica.mx/index.php/spm/article/view/11276/11857 [fecha de consulta: 03 de abril de 2020]. 
Requejo Rodríguez, Paloma (2001): “Suspensión o supresión de los derechos fundamentales?", en Revista de derecho político ( No 51), pp. 105-138. Disponible en: http://e-spacio.uned.es/fez/eserv.php?pid=bibliuned:DerechoPolitico-2001-51-13420\&dsID=PDF [fecha de consulta: 05 de abril de 2020].

Ríos Álvarez, Lautaro (2009): "Defensa Judicial de los Derechos Humanos en los estados de excepción”, en Estudios Constitucionales (Vol 7, № 1), pp. 277296. Disponible en: http://www.estudiosconstitucionales.cl/index.php/econstitucionales/article/view/246 [fecha de consulta: 05 de abril de 2020].

Robledo, Federico J. (2020): "Las garantías judiciales como vías de tutela de los derechos fundamentales en estados de emergencia (in) constitucional", en Estudios Constitucionales (Vol 8, No 2), pp. 247-292. Disponible en: http://www. estudiosconstitucionales.cl/index.php/econstitucionales/article/view/185/173 [fecha de consulta: 05 de abril de 2020].

Rotondo, Valerio (2020): “La decisión clínica en una situación de pandemia", en Actualidad Jurídica Iberoamericana (No Extra 12, 2), pp. 154-163. Disponible en: http://www.revista-aji.com/wp-content/uploads/2020/05/16._Valerio_Rotondo_pp._154-163.pdf [fecha de consulta: 30 de julio de 2020].

Ruiz Miquel, Carlos (2020): "Crisis del Coronavirus y crisis del Estado constitucional español”, en Diario La Ley (No 9656), pp. 1-17. Disponible en: https:// diariolaley.laleynext.es/dll/2020/o6/18/crisis-del-coronavirus-y-crisis-del-estado-constitucional-espanol [fecha de consulta: 29 de julio de 2020].

Sant'Ana Pedra, Adriano (2014): "Los deberes de las personas y la realización de los derechos fundamentales", en Estudios Constitucionales (Vol 12, № 2), pp. 13-28. Disponible en: http://www.estudiosconstitucionales.cl/index.php/ econstitucionales/article/view/17/17 [fecha de consulta: 04 de abril de 2020].

Serrano Sanz, José María (2020): "La economía y la pandemia", en El Cronista del Estado Social y Democrático de Derecho (No 86-87) pp. 110-113. Disponible en: http://www.elcronista.es/El-Cronista-n\%C3\%BAmero-86-87-Coronavirus. pdf [fecha de consulta: 03 de abril de 2020].

Simó Soler, Elisa (2020): "Política postCOVID-19: ¿vigilar y...? Cuestionamiento de una tecnología (des) humanizada", en Actualidad jurídica iberoamericana (Vol. 2, No Extra 12), pp. 788-795. Disponible en: http://www.revista-aji.com/ wp-content/uploads/2020/05/73._Elisa_Sim\%C3\%B3_pp._788-795.pdf [fecha de consulta: 12 de junio de 2020]. 
Talavera Fernández, Pedro Agustín (2008): "El derecho humano a la salud frente a las condiciones biosanitarias del planeta”, en Revista Europea de Derechos Fundamentales ( No 12), pp. 107-138.

Tórtora Aravena, Hugo (2010): "Las limitaciones a los derechos fundamentales", en Estudios Constitucionales (Vol 8, № 2), pp. 167-200. Disponible en: http://www.estudiosconstitucionales.cl/index.php/econstitucionales/article/ view/183/171 [fecha de consulta: 05 de abril de 2020].

Trilla García, Antoni (2020): "Un mundo, una salud: la epidemia por el nuevo coronavirus COVID-19", en Medicina clínica (Vol. 154, No 5), pp. 175-177.

Valerio, Carlos (2020), "Derechos Humanos, Principio Precautorio y Covid 19", en Actualidad del derecho sanitario ( $\mathrm{N}^{\circ} 280$ ), pp. 439-445.

Velasco Caballero, Francisco (2020): "Estado de alarma y distribución territorial del poder", en El Cronista del Estado Social y Democrático de Derecho (No 86-87) pp. 78-87. Disponible en: http://www.elcronista.es/El-Cronista-n\%C3\%BAmero-86-87-Coronavirus.pdf [fecha de consulta: 05 de abril de 2020].

Vidal Martínez, Jaime (2015): “Acerca del Derecho a la protección de la salud en relación con los avances en biomedicina desde la perspectiva del Derecho español", en Actualidad Jurídica Iberoamericana ( $\mathrm{N}^{\circ}$ 2), pp. 1-42. Disponible en: http://www.revista-aji.com/articulos/2015/1-42.pdf [fecha de consulta: 30 de julio de 2020].

Wunder Hachem, Daniel (2014): “Derechos fundamentales económicos y sociales y la responsabilidad del Estado por omisión”, en Estudios Constitucionales (Vol 12, No 1), pp. 285-328. Disponible en: http://www.estudiosconstitucionales. cl/index.php/econstitucionales/article/view/7/7 [fecha de consulta: 05 de abril de 2020].

ZúñIga Fajuri, Alejandra (2011): "El Derecho a la vida y el Derecho a la protección de la salud en la Constitución: una relación necesaria", en Estudios Constitucionales (Vol 9, No 1), pp. 37-64. Disponible en: http://www.estudiosconstitucionales.cl/index.php/econstitucionales/article/view/164/152 [fecha de consulta: 05 de abril de 2020].

\section{Normas jurídicas citadas}

Constitución Española. Boletín Oficial del Estado, 29 de diciembre de 1978.

Ley Orgánica 4/1981, de 1 de junio, de los estados de alarma, excepción y sitio. Boletín Oficial del Estado, 5 de junio de 1981. 
Ley Orgánica 3/1986, de 14 de abril, de Medidas Especiales en Materia de Salud Pública. Boletín Oficial del Estado, 29 de abril de 1986.

Ley 14/1986, de 25 de abril, General de Sanidad. Boletín Oficial del Estado, 29 de abril de 1986.

Carta Social Europea. Consejo de Europa, de o3 de mayo de 1996.

Ley Orgánica 1/2004, de 28 de diciembre, de Medidas de Protección Integral contra la Violencia de Género. Boletín Oficial del Estado, 29 de diciembre de 2004. Carta de los Derechos Fundamentales de la Unión Europea (2000/C 364/01). Diario Oficial de las Comunidades Europeas, 18 diciembre 2000.

Convenio Europeo de Derechos Humanos, o4 de noviembre de 1950.

Ley 13/2011, de 27 de mayo, de regulación del juego. Boletín Oficial del Estado, 28 de mayo de 2011.

Ley 33/2011, de 4 de octubre, General de Salud Pública. Boletín Oficial del Estado, 5 de octubre de 2011.

Instrumento de ratificación del Convenio del Consejo de Europa sobre prevención y lucha contra la violencia contra la mujer y la violencia doméstica, hecho en Estambul el 11 de mayo de 2011. Boletín Oficial del Estado, 6 de junio de 2014.

Ley 17/2015, de 9 de julio, del Sistema Nacional de Protección Civil. Boletín Oficial del Estado, 10 de julio de 2015.

Real Decreto-ley 9/2018, de 3 de agosto, de medidas urgentes para el desarrollo del Pacto de Estado contra la violencia de género. Boletín Oficial del Estado, 4 de agosto de 2018.

Ley Orgánica 5/2018, de 28 de diciembre, de reforma de la Ley Orgánica 6/1985, de 1 de julio, del Poder Judicial, sobre medidas urgentes en aplicación del Pacto de Estado en materia de violencia de género. Boletín Oficial del Estado, 29 de diciembre de 2018.

Ley 3/2019, de 1 de marzo, de mejora de la situación de orfandad de las hijas e hijos de víctimas de violencia de género y otras formas de violencia contra la mujer. Boletín Oficial del Estado, 2 de marzo de 2019.

Real Decreto 463/2020, de 14 de marzo, por el que se declara el estado de alarma para la gestión de la situación de crisis sanitaria ocasionada por el COVID-19. Boletín Oficial del Estado, 14 de marzo de 2020.

Orden INT/226/2020, de 15 de marzo, por la que se establecen criterios de actuación para las Fuerzas y Cuerpos de Seguridad en relación con el Real Decreto 
463/2020, de 14 de marzo, por el que se declara el estado de alarma para la gestión de la situación de crisis sanitaria ocasionada por el COVID-19. Boletín Oficial del Estado, 15 de marzo de 2020.

Orden INT/228/2020, de 15 de marzo, por la que se establecen criterios de aplicación del Real Decreto 463/2020, de 14 de marzo, por el que se declara el estado de alarma para la gestión de la situación de crisis sanitaria ocasionada por el COVID-19, en el ámbito del Sistema Nacional de Protección Civil. Boletín Oficial del Estado, 15 de marzo de 2020.

Orden $\mathrm{SND} / 233 / 2020$, de 15 de marzo, por la que se establecen determinadas obligaciones de información de acuerdo con lo previsto en el Real Decreto 463/2020, de 14 de marzo, por el que se declara el estado de alarma para la gestión de la situación de crisis sanitaria ocasionada por el COVID-19. Boletín Oficial del Estado, 15 de marzo de 2020.

Orden INT/227/2020, de 15 de marzo, en relación con las medidas que se adoptan en el ámbito de Instituciones Penitenciarias al amparo del Real Decreto 463/2020, de 14 de marzo, por el que se declara el estado de alarma para la gestión de la situación de crisis sanitaria ocasionada por el COVID-19. Boletín Oficial del Estado, 15 de marzo de 2020.

Real Decreto 465/2020, de 17 de marzo, por el que se modifica el Real Decreto 463/2020, de 14 de marzo, por el que se declara el estado de alarma para la gestión de la situación de crisis sanitaria ocasionada por el COVID-19. Boletín Oficial del Estado, 18 de marzo de 2020.

Decreto-ley 1/2020, de 18 de marzo, por el que se establecen medidas liberalizadoras de los horarios de apertura de las actividades comerciales habilitadas por el Real Decreto 463/2020, de 14 de marzo, por el que se declara el estado de alarma para la gestión de la situación de crisis sanitaria ocasionado por el COVID 19. Diario Oficial de Extremadura, 20 de marzo de 2020.

Decreto-ley Foral 1/2020, de 18 de marzo, por el que se aprueban medidas urgentes para responder al impacto generado por la crisis sanitaria del coronavirus (COVID-19). Boletín Oficial de Navarra, 19 de marzo de 2020.

Orden SND/257/2020, de 19 de marzo, por la que se declara la suspensión de apertura al público de establecimientos de alojamiento turístico, de acuerdo con el artículo 10.6 del Real Decreto 463/2020, de 14 de marzo, por el que se declara el estado de alarma para la gestión de la situación de crisis sanitaria ocasionada por el COVID-19. Boletín Oficial del Estado, 19 de marzo de 2020. 
Orden TMA/258/2020, de 19 de marzo, por la que se dictan disposiciones respecto de los títulos administrativos y las actividades inspectoras de la administración marítima, al amparo del Real Decreto 463/2020, de 14 de marzo, por el que se declara el estado de alarma para la gestión de la situación de crisis sanitaria ocasionada por el COVID-19. Boletín Oficial del Estado, 20 de marzo de 2020.

Orden SND/261/2020, de 19 de marzo, para la coordinación de la actividad profesional de los miembros de los cuerpos de funcionarios regulados en el libro VI de la Ley Orgánica 6/1985, de 1 de julio, del Poder Judicial durante la vigencia del estado de alarma declarado por Real Decreto 463/2020, de 14 de marzo. Boletín Oficial del Estado, 20 de marzo de 2020.

Orden INT/262/2020, de 20 de marzo, por la que se desarrolla el Real Decreto 463/2020, de 14 de marzo, por el que se declara el estado de alarma para la gestión de la situación de crisis sanitaria ocasionada por el COVID-19, en materia de tráfico y circulación de vehículos a motor. Boletín Oficial del Estado, 21 de marzo de 2020.

Resolución de 20 de marzo de 2020, de la Dirección General de Aviación Civil, por la que se establecen las condiciones para la prestación y se adjudica de forma directa el servicio de transporte aéreo en las rutas aéreas Palma de Mallorca-Menorca y Palma de Mallorca-Ibiza durante el estado de alarma declarado con motivo del COVID-19. Boletín Oficial del Estado, 21 de marzo de 2020.

Resolución de 20 de marzo de 2020, de la Comisión Nacional del Mercado de Valores, sobre la suspensión de plazos administrativos prevista en el Real Decreto 463/2020, relativo al estado de alarma. Boletín Oficial del Estado, 25 de marzo de 2020 .

Orden APA/288/2020, de 24 de marzo, por la que se modifican determinados plazos para la tramitación de los procedimientos establecidos en el Real Decreto 1363/2018, de 2 de noviembre, para la aplicación de las medidas del programa de apoyo 2019-2023 al sector vitivinícola español para el año 2020, como consecuencia de la aplicación del estado de alarma declarado por el Real Decreto 463/2020, de 14 de marzo. Boletín Oficial del Estado, 26 de marzo de 2020.

Orden INT/284/2020, de 25 de marzo, por la que se modifica la Orden INT/262/2020, de 20 de marzo, por la que se desarrolla el Real Decreto 463/2020, de 14 de marzo, por el que se declara el estado de alarma para la gestión de la situación de crisis sanitaria ocasionada por el COVID-19, en materia 
de tráfico y circulación de vehículos a motor. Boletín Oficial del Estado, 26 de marzo de 2020.

Real Decreto 476/2020, de 27 de marzo, por el que se prorroga el estado de alarma declarado por el Real Decreto 463/2020, de 14 de marzo, por el que se declara el estado de alarma para la gestión de la situación de crisis sanitaria ocasionada por el COVID-19. Boletín Oficial del Estado, 28 de marzo de 2020.

Orden SND/299/2020, de 27 de marzo, por la que se modifica la Orden $\mathrm{SND} / 232 / 2020$, de 15 de marzo, por la que se adoptan medidas en materia de recursos humanos y medios para la gestión de la situación de crisis sanitaria ocasionada por el COVID-19. Boletín Oficial del Estado, 30 de marzo de 2020. Resolución de 27 de marzo de 2020, de la Dirección General de Aviación Civil, por la que se establecen las condiciones para la prestación, y se adjudica de forma directa, el servicio de transporte aéreo en determinadas rutas aéreas del Archipiélago Canario durante el estado de alarma declarado con motivo del COVID-19. Boletín Oficial del Estado, 31 de marzo de 2020.

Resolución de 27 de marzo de 2020, de la Dirección General de Aviación Civil, por la que se modifica la duración, y se prorroga la adjudicación, del servicio de transporte aéreo en las rutas aéreas Palma de Mallorca-Menorca y Palma de Mallorca-Ibiza durante el estado de alarma declarado con motivo del COVID-19. Boletín Oficial del Estado, 31 de marzo de 2020.

Real Decreto-ley 11/2020, de 31 de marzo, por el que se adoptan medidas urgentes complementarias en el ámbito social y económico para hacer frente al COVID-19. Boletín Oficial del Estado, 1 de abril de 2020.

Orden TMA/309/2020, de 31 de marzo, por la que se modifica la Orden TMA/258/2020, de 19 de marzo, por la que se dictan disposiciones respecto de los títulos administrativos y las actividades inspectoras de la administración marítima, al amparo del Real Decreto 463/2020, de 14 de marzo, por el que se declara el estado de alarma para la gestión de la situación de crisis sanitaria ocasionada por el COVID-19. Boletín Oficial del Estado, 1 de abril de 2020.

Real Decreto-ley 12/2020, de 31 de marzo, de medidas urgentes en materia de protección y asistencia a las víctimas de violencia de género. Boletín Oficial del Estado, 1 de abril de 2020.

Orden TMA/311/2020, de 1 de abril, por la que se disponen medidas para la gestión del mantenimiento de los vehículos ferroviarios en la situación de crisis 
sanitaria ocasionada por el COVID-19. Boletín Oficial del Estado, 2 de abril de 2020.

Orden SND/319/2020, de 1 de abril, por la que se modifica la Orden SND/232/2020, de 15 de marzo, por la que se adoptan medidas en materia de recursos humanos y medios para la gestión de la situación de crisis sanitaria ocasionada por el COVID-19. Boletín Oficial del Estado, 3 de abril de 2020.

Orden $\mathrm{SND} / 322 / 2020$, de 3 de abril, por la que se modifican las Orden $\mathrm{SND} / 275 / 2020$, de 23 de marzo y la Orden SND/295/2020, de 26 de marzo, y se establecen nuevas medidas para atender necesidades urgentes de carácter social o sanitario en el ámbito de la situación de la crisis sanitaria ocasionada por el COVID-19. Boletín Oficial del Estado, 4 de abril de 2020.

Orden SND/275/2020, de 23 de marzo, por la que se establecen medidas complementarias de carácter organizativo, así como de suministros de información en el ámbito de los centros de servicios sociales de carácter residencial en relación con la gestión de la crisis sanitaria ocasionada por el COVID-19. Boletín Oficial del Estado, 24 de marzo de 2020.

Orden SND/295/2020, de 26 de marzo, por la que se adoptan medidas en materia de recursos humanos en el ámbito de los servicios sociales ante la situación de crisis ocasionada por el COVID-19. Boletín Oficial del Estado, 28 de marzo de 2020.

Real Decreto 476/2020, de 27 de marzo, por el que se prorroga el estado de alarma declarado por el Real Decreto 463/2020, de 14 de marzo, por el que se declara el estado de alarma para la gestión de la situación de crisis sanitaria ocasionada por el COVID-19. Boletín Oficial del Estado, 28 de marzo de 2020.

Real Decreto 514/2020, de 8 de mayo, por el que se prorroga el estado de alarma declarado por el Real Decreto 463/2020, de 14 de marzo, por el que se declara el estado de alarma para la gestión de la situación de crisis sanitaria ocasionada por el COVID-19. Boletín Oficial del Estado, 9 de mayo de 2020.

Real Decreto 487/2020, de 10 de abril, por el que se prorroga el estado de alarma declarado por el Real Decreto 463/2020, de 14 de marzo, por el que se declara el estado de alarma para la gestión de la situación de crisis sanitaria ocasionada por el COVID-19. Boletín Oficial del Estado, 11 de abril de 2020.

Orden SND/354/2020, de 19 de abril, por la que se establecen medidas excepcionales para garantizar el acceso de la población a los productos de uso reco- 
mendados como medidas higiénicas para la prevención de contagios por el COVID-19. Boletín Oficial del Estado, 19 de abril de 2020.

Real Decreto 492/2020, de 24 de abril, por el que se prorroga el estado de alarma declarado por el Real Decreto 463/2020, de 14 de marzo, por el que se declara el estado de alarma para la gestión de la situación de crisis sanitaria ocasionada por el COVI-19. Boletín Oficial del Estado, 25 de abril de 2020.

Real Decreto 537/2020, de 22 de mayo, por el que se prorroga el estado de alarma declarado por el Real Decreto 463/2020, de 14 de marzo, por el que se declara el estado de alarma para la gestión de la situación de crisis sanitaria ocasionada por el COVID-19. Boletín Oficial del Estado, 23 de mayo de 2020.

Real Decreto 555/2020, de 5 de junio, por el que se prorroga el estado de alarma declarado por el Real Decreto 463/2020, de 14 de marzo, por el que se declara el estado de alarma para la gestión de la situación de crisis sanitaria ocasionada por el COVID-19. Boletín Oficial del Estado, 6 de junio de 2020.

Real Decreto-ley 21/2020, de 9 de junio, de medidas urgentes de prevención, contención y coordinación para hacer frente a la crisis sanitaria ocasionada por el COVID-19. Boletín Oficial del Estado, 10 de junio de 2020. 